\title{
Vitamin D levels in patients with recurrent aphthous stomatitis
}

\author{
Aynure Öztekin ${ }^{*}$ and Coşkun Öztekin ${ }^{2}$
}

\begin{abstract}
Background: Lower serum vitamin D levels, a major public health problem worldwide, has been found to be associated with various infectious diseases, cancers, autoimmune and dermatological diseases. The serum levels of vitamin D in patients with recurrent aphthous stomatitis are not clear. We investigated the vitamin D levels in patients with recurrent aphthous stomatitis.

Methods: Forty patients with recurrent aphthous stomatitis (Group I) and 70 healthy controls (Group II) included in the study. The characteristics of aphthous lesions (duration of disease and remission, frequency, diameter and number of the lesions) and demographics of the participants were recorded. Serum 25-hydroxycholecalciferol levels were measured using electrochemiluminescence binding method.

Results: There was no statistically significant difference between the groups in terms of age $(p=0.06)$ and sex $(p=0.4)$. Other baseline characteristics were not significantly different between the groups $(p>0.05$ for all). The mean diameter of aphthous lesions was $0.5(0.4-0.6) \mathrm{cm}$ and the mean number of lesions was $2.2 \pm$ 1.5. Serum vitamin D levels were $11 \pm 7.04 \mathrm{ng} / \mathrm{ml}$ in Group I and $16.4 \pm 10.19 \mathrm{ng} / \mathrm{ml}$ in Group II. Serum vitamin D levels were significantly lower in patients with recurrent aphthous stomatitis $(p=0.004)$.
\end{abstract}

Conclusions: The present study showed lower vitamin D levels in patients with recurrent aphthous stomatitis compared to healthy controls.

\section{Introduction}

Aphthous stomatitis is the painful ulcers of the oral mucous membranes. These idiopathic noninfectious lesions are characterized by recurrent painful attacks (commonly known as "canker sores"). Aphthous stomatitis affects approximately $20 \%$ of the general population [1]. Risk factors include local trauma, emotional or physiologic stress, allergy, toxin exposure, vitamin deficiency, poor oral hygiene, menstruation, and alterations in the oral flora [1].

Recent studies investigated the role of several vitamins including vitamin B1, B2, B6, B12 and folic acid in the etiopathogenesis of recurrent aphthous stomatitis [2-5]. Nolan et al. [2] found that $28 \%$ of 60 patients with recurrent oral ulcers had a deficiency in at least one of the $\mathrm{B} 1, \mathrm{~B} 2$, and B6 vitamins. Replacement therapy in these deficient individuals with recurrent oral ulcers displayed a significant improvement within 1 month. Lalla et al.

\footnotetext{
* Correspondence: aynureoztekin@gmail.com

${ }^{1}$ Department of Dermatology, Hitit University Medical School, Çorum, Turkey Full list of author information is available at the end of the article
}

[6] evaluated the effect of daily multivitamin supplementation (vitamins A, B1, B2, B3, B5, B6, B9, B12, C, D, and $\mathrm{E}$ ) on the number and duration of recurrent aphthous stomatitis episodes but found no significant improvement in the number or duration of episodes. In contrast, Petersen et al. [7, 8] reported significant improvement in the number of recurrent aphthous lesions using combination vitamin/herbal supplement even in the absence of serologic vitamin deficiency.

Vitamin D is a fat-soluble secosteroid and functions primarily in the regulation of the calcium and phosphorus balance [9]. Recent studies over the past years have revealed a broader role of vitamin D; not only in skeletal and cardiovascular disorders but also in cancers, central nervous system diseases, infections, autoimmune, and dermatological disorders [10]. It is known that the risk factors for the development of autoimmune diseases are a mosaic, which includes family history, genetic predisposition, hormonal status and environmental features. In accordance, lower vitamin D levels and vitamin D receptor polymorphism has been suggested as important 
risk factors for the development of autoimmune diseases [11]. Previous studies indicate that innate and acquired immunity play an important role in the development of recurrent aphthous stomatitis [12].

The role of vitamin D deficiency in patients with recurrent aphthous stomatitis is not well known. The aim of the present study is to investigate the serum levels of vitamin D in patients with recurrent aphthous stomatitis.

\section{Methods}

This cross-sectional study complied with the tenets of the Declaration of Helsinki and was approved by the Ethical Committee of Atatürk University, Erzurum, Turkey. Written informed consent was obtained from all the participants before the study. This study was conducted in the Dermatology Clinic of Palandöken State Hospital, Erzurum, Turkey.

A total of 40 patients with recurrent aphthous stomatitis (Group I) and 70 healthy controls (Group II) were included in the study. Participants were 18 years and older with a validated history of at least three episodes of idiopathic recurrent aphthous stomatitis within the previous 12 months. Only minor aphthous lesions < $1 \mathrm{~cm}$ in diameter were included in the study. One experienced investigator evaluated participants about the location, duration, frequency, diameter, number, and appearance of aphthous lesions. Exclusion criteria were as follows: (1) age $<18$ years and $>50$ years, (2) presence of systemic disease that can cause oral ulceration, (3) pregnancy and lactation (4) use of vitamin D supplementation within last 6 months. Participants in the control group consisted of healthy volunteers who had no complaints and systemic disease.

Age, gender, marital status, level of education, place of residence (rural or urban), smoking and alcohol use, and drug use characteristics of all participants were recorded. Diagnosis of recurrent aphthous stomatitis was based on physical examinations by an experienced dermatologist and patient history.

\section{Serum collection}

Blood from the forearm vein was collected into 5-ml Vacutainer tubes with no anticoagulant. The blood samples were centrifuged $\left(1000 \times \mathrm{g}, 15 \mathrm{~min}, 4^{\circ} \mathrm{C}\right)$ to separate serum. Serum was removed and immediately stored at $-80{ }^{\circ} \mathrm{C}$ until analyzed.

\section{Biochemical measurements}

Serum 25-hydroxycholecalciferol measurements were performed using electrochemiluminescence binding method (COBAS reagent kit; COBAS e601 analyzer series, Roche Diagnostics, Basel, Switzerland). The results were expressed in $\mathrm{ng} / \mathrm{dl}$.

\section{Statistical analysis}

All data were entered into a spreadsheet, and statistical analyses were performed using R 3.3.2v (open source). Data are shown as mean \pm standard deviation for continuous variables, as median (minimum-maximum) for ordinal variables, and as frequency with percent for categorical variables. To evaluate the level of data normality for continuous variables, the Kolmogorov Smirnov test was used. Categorical comparisons were made by chi-square test. Independent sample t-test was used for comparing the means of continuous variables.

For more than two independent groups, the Kruskal Wallis test was used for non-normally distributed variables. A Spearman's rho correlation was used to analyze the association between non-normally distributed variables. Correlations between normally distributed variables were analyzed by Pearson's correlation coefficient. A $p$ value of $<0.05$ was considered statistically significant.

\section{Results}

A total of 40 patients ( 25 females, 15 males) were included in Group I and 70 healthy individuals in Group II (38 females and 32 males). The mean age of the participants in Group I was $31.2 \pm 10.05$ years and in Groups II was $27.44 \pm 7.96$ years. There was no statistically significant difference between the groups in terms of age $(p=0.06)$ and gender $(p=0.4)$. Other baseline characteristics including marital status, level of education, and place of residence were not significantly different between the groups ( $p>0.05$ for all). Table 1 summarizes the demographics and baseline characteristics of the groups in detail.

Table 1 Demographics and baseline characteristics of the groups

\begin{tabular}{llll}
\hline & \multicolumn{2}{l}{ Groups } & P value \\
\cline { 2 - 3 } & Group I & Control & \\
\hline Age (years) & $31.20 \pm 10.05$ & $27.44 \pm 7.96$ & 0.06 \\
Sex & & & \\
Male & $15(37.5)$ & $32(45.71)$ & 0.4 \\
Marital status & $25(62.5)$ & $38(54.29)$ & \\
$\quad$ Married & & & \\
Single & $26(65)$ & $34(48.6)$ & 0.1 \\
Level of education & $14(35)$ & $36(51.4)$ & \\
Primary school & $14(35)$ & $16(22.86)$ & 0.07 \\
Secondary school & $7(17.5)$ & $4(5.71)$ & \\
High school & $9(22.5)$ & $23(32.86)$ & \\
$\quad$ University & $10(25)$ & $27(38.57)$ & \\
Place of residence & & & \\
Rural & $5(12.5)$ & $7(10)$ & 0.76 \\
Urban & $35(87.5)$ & $63(90)$ & \\
\hline
\end{tabular}


One patient $(2.5 \%)$ was smoking and none of the patients $(1.82 \%)$ were using alcohol in Group I. Ten patients $(25 \%)$ had a history of drug use in Group I. Twenty-one patients (52.5\%) had a family history of aphthous stomatitis.

The mean duration of recurrent aphthous stomatitis was 42 (24-65) months. The mean diameter of the lesions was $0.5(0.4-0.6) \mathrm{cm}$. The mean number of the lesions per patient was $2(1-7)$. The mean frequency of recurrence was 15 (7-90) days. The mean healing time was $8.2 \pm 3.38$ days. The mean duration of remission was 7 (5-14) months. There was no significant correlation between serum vitamin $\mathrm{D}$ levels and the diameter of the aphthous lesions $(r=0.044, p=0.79)$, the numbers of lesions $(r=0.074, p=0.651)$, and the mean healing time ( $r$ $=0.013, p=0.935)$.

Serum vitamin D levels were $11.00 \pm 7.03 \mathrm{ng} / \mathrm{ml}$ in Group I and $16.40 \pm 10.19 \mathrm{ng} / \mathrm{ml}$ in Group II. There was a statistically significant difference between the groups in terms of serum vitamin D levels $(p=0.004)$. Male patients with recurrent aphthous stomatitis had a higher serum vitamin $\mathrm{D}$ levels compared to female patients $(15.27 \pm 6.94$ versus $8.44 \pm 5.82)$ in Group I $(p=0.002)$. Figure 1 shows the mean serum vitamin D concentrations of the groups in an error bar graph.

\section{Discussion}

This study evaluated the vitamin D levels in the serum of patients with recurrent aphthous stomatitis. We found decreased levels of vitamin D in the serum of patients with recurrent aphthous stomatitis compared to healthy control subjects.

Since the exact etiology of recurrent aphthous stomatitis is unknown, there is no effective and curative therapy. Current treatment options (topical analgesics, antiseptics, corticosteroids and systemic therapy) are nonspecific and have limited efficacy. The role of multivitamin supplementation including vitamin $\mathrm{D}$ in the treatment of recurrent aphthous stomatitis is controversial and published studies reported conflicting results [6-8]. Children with periodic fever, aphthous stomatitis, pharyngitis, and cervical adenitis (PFAPA) syndrome have decreased levels of vitamin $\mathrm{D}$ and replacement treatment seems to significantly reduce the typical PFAPA episodes and their duration [13, 14]. Further studies are necessary to confirm the role of vitamin D in the treatment of recurrent aphthous stomatitis.

The major source of vitamin D in humans is endogenous synthesis in the skin with the help of sunshine. Salmon, mackerel, caviar, and eggs are the other sources of vitamin D [15]. Vitamin D deficiency/insufficiency at all ages is a major public health problem worldwide [16]. It is not only related with rickets but also with a wide variety of diseases including neoplastic, cardiovascular and autoimmune diseases. There are only several preliminary studies present in the literature evaluating vitamin D levels in patients with aphthous stomatitis. Khabbazi et al. [17], compared the serum 25-hydroxy vitamin D levels in idiopathic minor recurrent aphthous stomatitis patients with age and sex-matched healthy controls. They found that 25-hydroxy vitamin $\mathrm{D}$ levels were significantly lower in the study group $(12.1 \mathrm{ng} / \mathrm{dl}$ vs $27.4 \mathrm{ng} / \mathrm{dl})$. In consistent with this study, we found lower levels of serum 25-hydroxy vitamin D in patients with recurrent aphthous stomatitis compared to healthy individuals with similar age and gender distribution. Another study by Krawiecka et al. [18], reported no significant difference between patients with recurrent aphthous stomatitis and healthy individuals in terms of serum vitamin D levels. Decreased vitamin D levels have

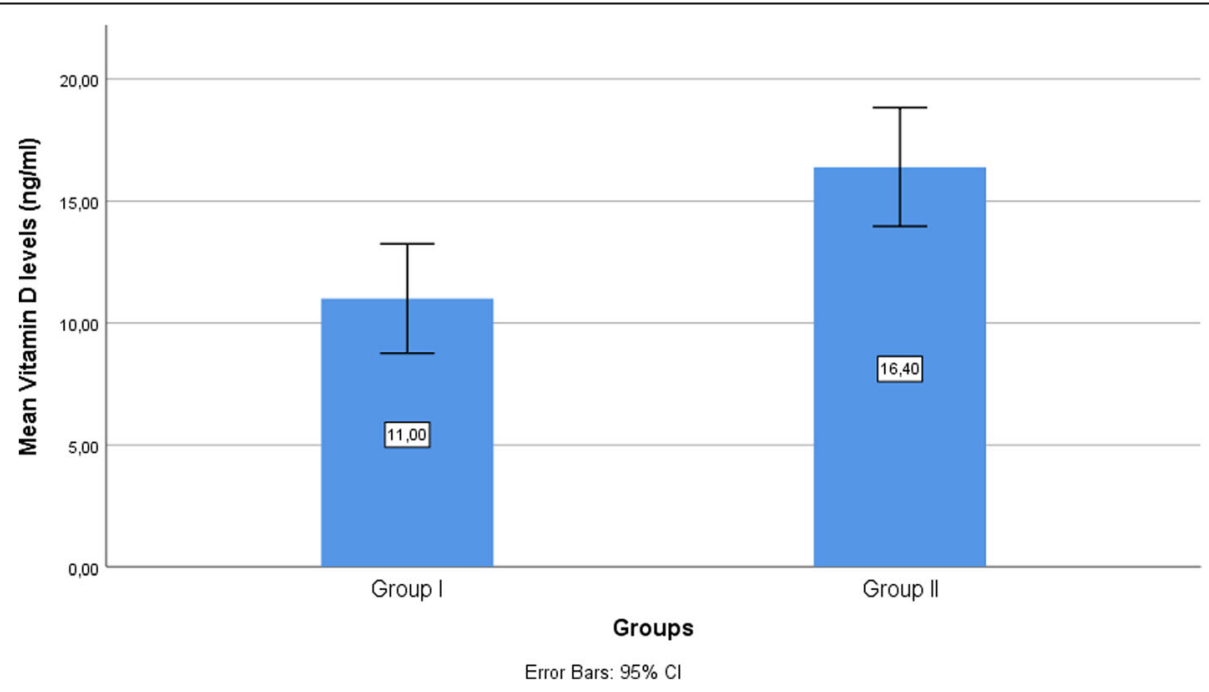

Fig. 1 The mean serum vitamin D concentrations of the groups in an error bar graph 
been reported in various several disorders, including multiple sclerosis, infectious diseases, diabetes mellitus, systemic lupus erythematosus, rheumatoid arthritis, inflammatory bowel disease, thyroiditis and autoimmune gastritis [19-22]. We found significantly lower levels of vitamin $\mathrm{D}$ in patients with recurrent aphthous stomatitis. However, it is not clear whether vitamin D deficiency is the cause or rather a consequence of the disease.

Another finding of the present study is that male patients have higher serum vitamin D levels compared to female patients with recurrent aphthous stomatitis. There are conflicting results among the studies regarding vitamin $\mathrm{D}$ level differences by gender in the literature [23, 24]. Al-Horani et al. [23], found the serum vitamin $\mathrm{D}$ concentrations in young males and females were $25.82 \mathrm{ng} / \mathrm{ml}$ and $21.95 \mathrm{ng} / \mathrm{mL}$, respectively. However, in a longitudinal study by Khosravi-Boroujeni [23] reported slightly higher vitamin D levels and lower vitamin $\mathrm{D}$ deficiency in female participants compared to males.

Altunsoy et al. [25], reported the serum levels of 25 $(\mathrm{OH})$ vitamin $\mathrm{D}$ in healthy adults with a mean age of 37.58 years (23 male, 17 female) as $22.31 \pm 8.8 \mathrm{ng} / \mathrm{ml}$. Another study found that the median value of $25(\mathrm{OH})$ vitamin $\mathrm{D}$ in 50 healthy adults with a mean age of 53.44 \pm 8.422 years as $22(6-40) \mathrm{ng} / \mathrm{ml}$ [26]. In the present study, we have found a relatively lower levels of $25(\mathrm{OH})$ vitamin D levels compared to previous studies in our healthy control group $(16.40 \pm 10.19 \mathrm{ng} / \mathrm{ml})$. It is well known that measurement of $25(\mathrm{OH})$ vitamin D levels is the best indicator of the vitamin D status in human. The measurement and standardization of $25(\mathrm{OH})$ vitamin D levels remains challenging for various reasons. These reasons may include patient related factor (e.g. ethnicity, age, gender), methodological factors (e.g. chemiluminescent immunoassay, high-performance liquid chromatography, radioimmunoassay), and others (e.g. season, geographic location) [27-29]. For example; the correlation between two automated assays in terms of the measurements of serum vitamin D levels was found to be fair and these two methods (the Cobas ${ }^{\oplus}$ Total Vitamin D Assay and the Liaison $\mathrm{XL}^{\circ}$ Total Vitamin D Assay) showed significant bias [28]. Therefore, it would be more meaningful to compare the results of the study within itself until a universal standardization of vitamin D level was established according to factors mentioned before.

\section{Conclusions}

This article provides a significant contribution to the literature regarding levels of vitamin $D$ in patients with recurrent aphthous stomatitis. With our findings, and considering that Vitamin D replacement will not cause significant adverse effects, we recommend vitamin D as supportive treatment in patients with in recurrent aphthous stomatitis. Further studies with larger sample size are necessary to confirm our results and prospective randomized clinical trials will reveal the potential protective/therapeutic role of vitamin D in recurrent aphthous stomatitis.

\section{Abbreviation}

PFAPA: Periodic fever, aphthous stomatitis, pharyngitis, and cervical adenitis

\section{Acknowledgements \\ None \\ Funding \\ None}

Availability of data and materials

Most of the data generated or analysed during this study are included in this published article and its supplementary information. Details are available from the corresponding author upon reasonable request.

\section{Authors' contributions}

Study design: AO, CO. Performed the study: AO, CO. Analysed the data: AO, CO. Wrote the paper: AO, CO. All authors of this study have read and approved our manuscript, and this is the case.

\section{Ethics approval and consent to participate}

This study complied with the tenets of the Declaration of Helsinki and was approved by the Ethical Committee of Atatürk University, Erzurum, Turkey. Written informed consent was obtained from all the participants before the study.

\section{Consent for publication \\ Not Applicable}

\section{Competing interests}

The authors declare that they have no competing interests.

\section{Publisher's Note}

Springer Nature remains neutral with regard to jurisdictional claims in published maps and institutional affiliations.

\section{Author details}

'Department of Dermatology, Hitit University Medical School, Çorum, Turkey. ${ }^{2}$ Department of Family Medicine, Hitit University Medical School, Çorum, Turkey.

Received: 29 June 2018 Accepted: 29 October 2018 Published online: 09 November 2018

\section{References}

1. Porter SR, Hegarty A, Kaliakatsou F, et al. Recurrent aphthous stomatitis. Clin Dermatol. 2000;18:569-78.

2. Nolan A, Mclntosh WB, Allam BF, et al. Recurrent aphthous ulceration: vitamin B1, B2 and B6 status and response to replacement therapy. J Oral Pathol Med. 1991:20:389-91.

3. Wray D, Ferguson MM, Hutcheon WA, et al. Nutritional deficiencies in recurrent aphthae. J Oral Pathol. 1978;7:418-23.

4. Wray D, Ferguson MM, Mason DK, et al. Recurrent aphthae: treatment with vitamin B12, folic acid, and iron. Br Med J. 1975;2:490-3.

5. Porter S, Flint S, Scully C, et al. Recurrent aphthous stomatitis: the efficacy of replacement therapy in patients with underlying hematinic deficiencies. Ann Dent. 1992;51:14-6.

6. Lalla RV, Choquette LE, Feinn RS, et al. Multivitamin therapy for recurrent aphthous stomatitis: a randomized, double-masked, placebo-controlled trial. J Am Dent Assoc. 2012;143:370-6.

7. Pedersen A, Hougen HP, Klausen B, et al. LongoVital in the prevention of recurrent aphthous ulceration. J Oral Pathol Med. 1990;19:371-5. 
8. Pedersen A, Klausen B, Hougen HP, et al. Immunomodulation by LongoVital in patients with recurrent aphthous ulceration. J Oral Pathol Med. 1990;19: 376-80.

9. Ślebioda Z, Szponar E, Dorocka-Bobkowska B. Vitamin D and its relevance in the etiopathogenesis of oral cavity diseases. Arch Immunol Ther Exp. 2016; 64:385-97.

10. Kechichian E, Ezzedine K. Vitamin D and the skin: an update for dermatologists. Am J Clin Dermatol. 2017. https://doi.org/10.1007/s40257-017-0323-8.

11. Bizzaro G, Antico A, Fortunato A, et al. Vitamin $D$ and autoimmune diseases: is vitamin D receptor (VDR) polymorphism the culprit? Isr Med Assoc J. 2017:19:438-43.

12. Slebioda Z, Szponar E, Kowalska A. Etiopathogenesis of recurrent aphthous stomatitis and the role of immunologic aspects: literature review. Arch Immunol Ther Exp. 2014;62:205-15.

13. Stagi S, Bertini F, Rigante D, et al. Vitamin D levels and effects of vitamin D replacement in children with periodic fever, aphthous stomatitis, pharyngitis, and cervical adenitis (PFAPA) syndrome. Int J Pediatr Otorhinolaryngol. 2014;78:964-8.

14. Mahamid M, Agbaria K, Mahamid A, et al. Vitamin D linked to PFAPA syndrome. Int J Pediatr Otorhinolaryngol. 2013;77:362-4.

15. Calvo MS, Whiting SJ, Barton CN. Vitamin D fortification in the United States and Canada: current status and data needs. Am J Clin Nutr. 2004;80:1710S-6S

16. Sofi NY, Jain M, Kapil U, et al. Status of serum vitamin D and calcium levels in women of reproductive age in National Capital Territory of India. Indian J Endocrinol Metab. 2017:21:731-3.

17. Khabbazi A, Ghorbanihaghjo A, Fanood F, et al. A comparative study of vitamin $D$ serum levels in patients with recurrent aphthous stomatitis. Egypt Rheumatol. 2014;37:133-7.

18. Krawiecka E, Ślebioda Z, Szponar E, Kowalska A, Dorocka-Bobkowska B. Vitamin D status in recurrent aphthous stomatitis. Postepy Dermatol Alergol. 2017 Dec;34(6):612-7.

19. Agmon-Levin N, Theodor E, Segal RM, et al. Vitamin D in systemic and organspecific autoimmune diseases. Clin Rev Allergy Immunol. 2013;45:256-66.

20. Arnson Y, Amital H, Shoenfeld Y. Vitamin D and autoimmunity: new aetiological and therapeutic considerations. Ann Rheum Dis. 2007;66:1137-42.

21. Antico A, Tozzoli R, Giavarina D, et al. Hypovitaminosis D as predisposing factor for atrophic type A gastritis: a case-control study and review of the literature on the interaction of vitamin D with the immune system. Clin Rev Allergy Immunol. 2012;42:355-64.

22. Altieri B, Muscogiuri $G$, Barrea $L$, et al. Does vitamin D play a role in autoimmune endocrine disorders? A proof of concept. Rev Endocr Metab Disord. 2017;18:335-46.

23. Al-Horani H, Abu Dayyih W, Mallah E, et al. Nationality, gender, age, and body mass index influences on vitamin $D$ concentration among elderly patients and young Iraqi and Jordanian in Jordan. Biochem Res Int. 2016; 2016:8920503

24. Khosravi-Boroujeni H, Sarrafzadegan N, Sadeghi M, et al. Prevalence and trends of vitamin D deficiency among Iranian adults: a longitudinal study from 2001-2013. J Nutr Sci Vitaminol (Tokyo). 2017:63:284-90.

25. Altunsoy N, Yüksel RN, Cingi Yirun M, Killçarslan A, Aydemir Ç. Exploring the relationship between vitamin $D$ and mania: correlations between serum vitamin D levels and disease activity. Nord J Psychiatry. 2018;72:221-5.

26. Akgül F, Serçelik A, Çetin H, Erten T. Association of parathyroid hormone and vitamin $\mathrm{D}$ with untreated hypertension: is it different in white-coat or sustained hypertension? PLoS One. 2017;12:e0188669.

27. Man RE, Li LJ, Cheng CY, et al. Prevalence and determinants of suboptima vitamin D levels in a multiethnic asian population. Nutrients. 2017 Mar 22; 9(3):313.

28. Tré-Hardy M, Le Goff C, Gruson D. Testing of total 25(OH)vitamin D: agreement and discrepant cases between Cobas $^{\oplus} 8000$ and liaison ${ }^{\oplus} \mathrm{XL}$ methods. Clin Chem Lab Med. 2016;54:e391-4.

29. Kagotho E, Omuse G, Okinda N, Ojwang P. Vitamin D status in healthy black African adults at a tertiary hospital in Nairobi, Kenya: a cross sectional study. BMC Endocr Disord. 2018;18:70.

\section{Ready to submit your research? Choose BMC and benefit from:}

- fast, convenient online submission

- thorough peer review by experienced researchers in your field

- rapid publication on acceptance

- support for research data, including large and complex data types

- gold Open Access which fosters wider collaboration and increased citations

- maximum visibility for your research: over $100 \mathrm{M}$ website views per year

At BMC, research is always in progress.

Learn more biomedcentral.com/submissions 